\title{
Fatigue in lung cancer patients: symptom burden and management of challenges
}

\author{
This article was published in the following Dove Press journal: \\ Lung Cancer:Targets and Therapy \\ 9 May 2016 \\ Number of times this article has been viewed
}

\section{Simona Carnio \\ Rosario Francesco Di \\ Stefano \\ Silvia Novello}

Oncology Department, University of Turin, AOU San Luigi, Orbassano, Italy
Correspondence: Silvia Novello Oncology Department, University of Turin, AOU San Luigi, Regione

Gonzole 10, Orbassano, Turin 10043, Italy Email silvia.novello@unito.it

\begin{abstract}
Lung cancer (LC) remains the most common cause of cancer death in several countries across the world. Fatigue is the most frequently reported symptom in LC patients throughout the entire course of disease, and all international guidelines recommend early screening for cancer-related fatigue (CRF) and symptoms that can affect patients' quality of life. In patients with LC, fatigue belongs to the symptom cluster of pain, depression, and insomnia, which are commonly observed simultaneously, but are typically treated as separate although they may have common biological mechanisms. The treatment of CRF remains one of the difficult areas in the oncology field: scarce evidence supports pharmacological therapies, while some interesting data arising indicates alternative remedies and physical exercise seem to be one of the most effective approaches for CRF at any stage of LC.
\end{abstract}

Keywords: fatigue, lung cancer, symptom cluster, quality of life

\section{Introduction}

Lung cancer (LC) remains the most common cause of cancer-related death, accounting for approximately $20 \%$ of the total cancer death worldwide. Despite important progress occurring in diagnostic and therapeutic areas, only $10.9 \%$ of people with LC live 5 years or more. ${ }^{1}$ Several trials have shown that the physical symptoms have a great importance in cancer patients, especially in LC. ${ }^{2,3}$ A number of cluster symptoms such as anxiety, fatigue, and dyspnea have been associated with poor patient performance, and these often remain a major issue throughout the course of cancer treatment and thereafter. ${ }^{4}$ Cancer-related fatigue (CRF) is present during the entire course of the disease, resulting in the impairment of both day-to-day living and overall quality of life (QoL). ${ }^{5,6} \mathrm{CRF}$ is defined as a distressing, persistent, subjective sense of physical, emotional, and/or cognitive tiredness or exhaustion related to cancer and/or cancer treatment, and it is not strictly linked to recent activity and nor is it relieved by rest. ${ }^{7}$ Furthermore, patients with LC indicate relief from tiredness as the most common unmet need, even years after diagnosis. ${ }^{8}$ Fatigue is the most represented acute symptom before and after cancer treatment, affecting a large number of patients, ranging between $57 \%$ and $100 \%$ of the cases, ${ }^{9}$ rarely described as an isolated symptom and often associated with depression and sleep disorders. ${ }^{10}$ Different causes can justify the onset of fatigue in a patient with cancer, together with cancer itself, such as comorbidities, nutritional status, medications, the reduction of physical activity, and functional status. Different international guidelines have been published regarding the management of CRF, with no specific medication approved to date. ${ }^{7,11,12}$ Aware of the 
lack of data in the literature, this paper aims to summarize methods of identification and possible treatments of CRF in LC, with the purpose of suggesting a strategy for a more comprehensive and effective approach.

\section{Material and methods}

Articles from 1997 to 2016 were selected using PubMed, which is a very large research database, using as keywords only "fatigue" and "lung cancer". Subsequently, the articles were divided according to the different paragraphs of this review: assessment, fatigue and symptoms cluster, fatigue in several stages of disease, fatigue in active therapies, and, in conclusion, the possible therapeutic approaches. The data collected include more robust evidence and alternate strategy for managing fatigue in patients with LC. The management of this symptom must involve team effort, and for this reason our review paper is addressed to physicians and nurses.

\section{Assessment of CRF}

Fatigue has to be screened and scored according to the clinical practice guidelines. ${ }^{11-13}$ Any patient must, therefore, be evaluated for severity, duration, and alleviation of factors of CRF from the first visit and during the course of the disease. In addition, the type of fatigue must be identified, considering that CRF can be categorized as either primary or secondary. ${ }^{13}$ Primary fatigue is linked to the tumor itself or alterations caused by cytokines produced during cancer treatment $^{14}$ as a disturbance of hypothalamic regulatory circuits, ${ }^{15}$ changes in the central serotoninergic system, and alteration of circadian melatonin secretion. ${ }^{16}$ Factors playing a key role in fatigue development include polymorphisms in genes coding regulatory proteins of oxidative phosphorylation, signal transduction in B-cells, the expression of proinflammatory cytokines, and catecholamine metabolism. ${ }^{17}$ Secondary fatigue is caused by one or more disease-related symptom(s) such as sleep disturbance, infection, malnutrition, or anemia. Moreover, CRF can be closely linked to comorbidities, the presence of emotional distress or pain, the physical activity status, alcohol/substance abuse, and use of medications (Table 1). In the CRF evaluation, it is extremely relevant to consider the timing of the disease, in terms of recent diagnosis, disease progression/recurrence, follow-up period, or end of life. As previously mentioned, the correct identification and score of CFR is a fundamental step in treatment decision. Screening can be done through quantitative and semiquantitative scales, even if these assessments are more appropriate for secondary $\mathrm{CRF}$ and a validated scale, specific for CRF in LC, is currently not available. Among the
Table I Causes of CRF

\begin{tabular}{ll}
\hline Causes of CRF & \\
\hline Primary CRF & $\begin{array}{l}\text { Alterations caused by cytokines, disturbance of } \\
\text { hypothalamic regulatory circuits, changes in the } \\
\text { central nervous system serotoninergic system, } \\
\text { disturbance of circadian melatonin secretion, gene } \\
\text { polymorphisms for regulatory proteins of oxidative } \\
\text { phosphorylation }\end{array}$ \\
Secondary CRF & $\begin{array}{l}\text { Sleep disturbance, infection, anemia, malnutrition, } \\
\text { emotional distress, pain, reduced physical activity, } \\
\text { alcohol/substance abuse, use of medications, } \\
\text { comorbidities as COPD }\end{array}$ \\
\hline
\end{tabular}

Abbreviations: CRF, cancer-related fatigue; COPD, chronic obstructive pulmonary disease.

most used scales are the following: Brief Fatigue Inventory (BFI), Functional Assessment of Cancer Therapy-Fatigue, Cancer Fatigue Scale, Multidimensional Fatigue Inventory, and the European Organisation for Research and Treatment of Cancer Quality of Life Questionnaire-Core 30. ${ }^{18}$ BFI is the most common questionnaire included in LC clinical trials and is also useful in detecting the severity of fatigue occurring during the previous 24 hours together with the CRF impact on individual's life. Preliminary data reported in the literature suggest a possibility of integration of clinical and molecular assessment in detecting fatigue in LC. In fact, interesting data have been reported about the role of potential predictive biomarkers for primary CRF in non-small-cell lung cancer (NSCLC). A recent Chinese study showed, in 100 LC patients, a correlation of CRF and different factors such as tumor necrosis factor (TNF)- $\alpha$ and interleukin (IL)- 1 at the plasma level and 17-hydroxycorticosteroid in the urine, collected before and after chemotherapy. This correlation is statistically significant for TNF- $\alpha$ and IL-1, and fatigue was reported by $88 \%$ of patients. ${ }^{19}$ The use of validated scales (such as BFI) should always be applied to detect and grade fatigue in LC, not only in the research area but also in clinical practice.

\section{Fatigue and cluster symptoms}

The majority of patients with LC experience debilitating physical and psychological symptoms. Pain, depression, and fatigue are among the most frequent symptoms reported by LC patients, and their frequency and intensity increase with the approach of death $(P=0.001) .{ }^{20,21}$ Symptoms are commonly observed to co-occur in a related cluster and can be induced by common biological mechanisms, but are typically treated as separate entities. It has been established that depression is present in about one-third of patients with LC. In a group of 987 patients, depression before treatment was present in $322(33 \%)$ cases and persists in more than 50\% 
of them through the course of the disease. In this trial, it was shown that small-cell lung cancer (SCLC) patients had a threefold greater prevalence of depression than those with NSCLC (25\% versus $9 \% ; P<0.0001) .{ }^{22}$ It is estimated that $74 \%-90 \%$ of patients with LC experience pain, and several studies report similar rates of incidence for fatigue and insomnia. A recent study reports a simultaneous incidence of fatigue, pain, and insomnia, in the range of $40 \%-50 \%$ of cases. ${ }^{52}$ In another trial of 111 patients with solid cancer (the largest group with LC, 20\%), it was observed that the prevalence of pain, fatigue, insomnia, and somnolence were $100 \%$, $50 \%, 80 \%$, and $82 \%$, respectively. All the aforementioned rates suggest a strong correlation between fatigue, pain, and sleep disorders. ${ }^{23}$ Genetic polymorphisms in LC, such as mutant alleles in endothelial nitric oxide synthase, seem to be helpful in the identification of high-risk patients for these symptom clusters and also have the potential for development of personalized therapies. ${ }^{24} \mathrm{~A}$ qualitative study of LC patient symptoms indicates that the cluster of respiratory symptoms (such as cough and breathlessness) plays a central role in fatigue onset. ${ }^{6}$ Taking into consideration this type of interaction between symptom clusters, a single intervention should be successful to treat them simultaneously, and this approach could improve the perception of each single symptom. ${ }^{25}$

\section{Fatigue in early-stage LC and in survivors}

Improvements in curative therapies have led to increased number of cancer survivors: for this reason, recent guidelines have been published to detect, grade, and treat CRF in adult cancer survivors (including LC patients) after completion of primary treatment. ${ }^{12,26}$ The symptom in this specific subgroup of LC patients could be due to comorbidities and treatments prescribed to cope with surgical consequences and/or adjuvant chemo/radiotherapy. Nearly $60 \%$ of NSCLC survivors are affected by comorbidities, 50\% with forced expiratory volume in 1 second $\left(\mathrm{FEV}_{1}\right)<70 \%, 22 \%$ reported distressed mood, and $21 \%$ of them had severe functional restrictions. ${ }^{27}$ These deficits can promote the onset and/or worsening of fatigue, as reported in several publications. ${ }^{28,29}$ Among LC survivors, the prevalence of fatigue is close to $70 \%$ at 4 months after thoracotomy. ${ }^{30}$ In 350 patients surgically treated for early-stage NSCLC, the prevalence of fatigue was $57 \%$, with $47 \%$ of patients indicating mild fatigue and $17 \%$ experiencing moderate-to-severe fatigue. ${ }^{29}$ Recent data among 254 completely resected patients with stage IA (57.1\% of the population) or IB NSCLC (lobectomy was performed in $77.2 \%$ of cases) show an overall incidence of postoperative fatigue equal to $59.8 \%$ (37.4\% mild and $22.4 \%$ moderate-to-severe fatigue). The association between fatigue and functional status and $\mathrm{FEV}_{1} / \mathrm{FVC}$ (the proportion of a person's vital capacity that they are able to expire in the first second of forced expiration) was considered before and after surgery, with a mean time from surgery to evaluation equal to $2.9 \pm 1.5$ years. Before surgery, $59.8 \%$ of patients showed a slight decline in lung function $\left(\mathrm{FEV}_{1} / \mathrm{FVC}^{6} 1 \%-70 \%\right)$, and $43.3 \%$ had chronic bronchitis, chronic obstructive pulmonary disease (COPD), asthma, tuberculosis, or other lung diseases. The prevalence of anxiety and depression after surgery was $18.5 \%$ and $10.2 \%$, respectively, indicating that LC itself, together with the specific interventions, may have huge negative effects on the psychological wellbeing. It has been shown that moderate-to-severe fatigue was negatively associated with preoperative $\mathrm{FEV}_{1} / \mathrm{FVC}$ and physical activity and positively related to functional status, concurrent lung diseases, breathing difficulty, depression, and anxiety. ${ }^{31}$ Several studies demonstrated that functional status, concurrent lung diseases, depression, and anxiety are independent risk factors for fatigue, whereas physical activity was a protective factor. ${ }^{24,35} \mathrm{~A}$ recent meta-analysis found a strong negative correlation between $\mathrm{CRF}$ and continued smoking after surgical treatment. ${ }^{32}$ It is, therefore, strongly recommended to increase smoking cessation programs in this setting of patients: continuing smoking can worsen respiratory disorders already present, comorbidity, and also fatigue. Data about the persistence of fatigue in survivors are still controversial; one trial reported a resolution of symptoms ${ }^{33}$ at 3-6 months after surgery, ${ }^{33}$ while others have observed persistence for years after completion of treatment. ${ }^{34,35}$ In addition to the surgical approach, adjuvant treatment can also cause long-term toxicities: sensory neuropathy and hearing loss occured in approximately $45 \%$ and $21 \%$ of patients who underwent adjuvant platinum-based chemotherapy, together with worsening of CFR and decline of global QoL. ${ }^{36}$ In fact, in a phase III study of adjuvant chemotherapy (JBR.10 trial), global QoL of patients decreases both in the observation and chemotherapy arms, mainly because of fatigue and post surgical pain. Patients in the observation arm had a faster physical recovery: at 3 months. The QoL in patients who received chemotherapy was comparable to the observation arm at a median time of 9 months after surgery. ${ }^{37}$ In this trial, psychological distress was reported in almost $40 \%$ of NSCLC survivors, ${ }^{38}$ which is significantly higher than in other cancer survivors. Literature data provide evidence that the surgical and adjuvant therapies may, in some cases, lead to a reduced QoL, in particular with the appearance (or worsening) of the symptom cluster associated with the CFR. 


\section{Fatigue and active therapies in LC}

Patients receiving chemotherapy or radiotherapy report fatigue during treatment in $90 \%$ and from $65 \%$ to $100 \%$ of cases, respectively. ${ }^{39,40}$ Currently, physicians have few tools to cope with this symptom. A wide spectrum of health care needs is widely described by patients with LC and can be grouped into nine distinct domains: physical, daily living, psychological/emotional, spiritual/existential, informational, practical, communication, social and family related, and cognitive. It is well recognized that active treatment for LC causes a high physical impact on patients. ${ }^{41}$ In a recent prospective multicenter QoL study in patients treated for NSCLC, fatigue was the most frequently reported physical disorder. Before completing the questionnaires, almost $60 \%$ of patients had undergone chemotherapy and about $10 \%$ received radio- or chemotherapy. In the multivariate analysis including age, sex, tumor stage, and fatigue, only the latter was found to be an independent prognostic factor affecting survival..$^{42}$ In cancer patients (including LC patients) during chemotherapy treatment, diurnal variations of severe fatigue were identified. ${ }^{43,44}$ Morning and evening fatigue appear as distinct symptoms, both having a negative impact on prognosis. Interestingly, marital status, annual household income, body mass index, regular exercise, and a state of anxiety are associated only with morning fatigue, while among predictors of evening fatigue, child-care responsibilities, ethnicity (greater correlation with white patients), cancer diagnosis (patients with LC), and prior cancer treatment are reported as factors. Other factors like age, sex, functional status, comorbidity profile, depressive symptoms, sleep disturbance, and annual income of $<\$ 30,000$ may influence both morning and evening fatigue. In particular, younger age is associated with the highest levels with morning and evening fatigue. ${ }^{45,46}$ Data on the relationship between age and fatigue are also described in a trial which explored radiation therapy as a therapeutic approach. ${ }^{47}$ Different potential explanations for these results could be the administration of lower doses of chemotherapy for older patients, age-related changes in the hypothalamic-adrenal-pituitary axis, or even a "response shift" in the perception of symptoms in older patients. Another multicenter observational study with a large comprehensive spectrum of active anticancer treatments evaluated, using BFI scale, the incidence of CRF and pain in cancer patients: the largest group (42.6\%) comprised LC patients with ongoing anticancer treatment (or within a month), and approximately $60 \%$ demonstrated worse than moderate fatigue ${ }^{48}$ In the last 10 years, some targeted therapies (TT) entered the therapeutic armamentarium for advanced NSCLC, and these new drugs are also not devoid of side effects, such as fatigue ${ }^{49}$ An Italian multicenter survey evaluated the tolerance to TT in daily clinical practice, and about $65 \%$ of patients reported any grade of fatigue during treatment. ${ }^{50}$

\section{Therapeutic approaches for fatigue in LC}

Specific treatments for CFR have been investigated in a variety of solid tumors, and few data are currently available in LC. In this section, evidences with a greater impact on LC patients have been collected.

\section{Pharmacological treatments}

Medications with different mechanisms of action are used to treat CRF, including psychostimulants, phytotherapeutic agents, growth factors, corticosteroids, and antidepressants. However, for the majority of these approaches, there are no strong literature data supporting them as standard treatments. Studies with antidepressants, in particular with paroxetina, did not show a significant improvement of fatigue, unless in case of depressive disorder. ${ }^{51}$ Research has shown that $4 \mathrm{mg}$ dexamethasone is effective for CRF. ${ }^{52}$ Nevertheless, when dexamethasone is administered in patients undergoing chemotherapy to prevent nausea and/or allergy, at a dosage higher than $4 \mathrm{mg}$, fatigue is still reported. In a palliative context and for a short period of time, corticosteroids can improve CRF and increase patients' physical activity, but prolonged use should be avoided in view of the risk of steroid-induced myopathy. ${ }^{13}$ In the past, progestational steroids were often used for the treatment of fatigue. However, the results of a recent metaanalysis including four trials did not show differences between progestational steroids versus placebo. ${ }^{51}$ Different publications describe the effectiveness of psychostimulant agents, such as psychostimulants methylphenidate and modafinil, 53,54 in the treatment of severe CRF, although frequent and continuous use of these drugs is not recommended because of the related side effects. Methylphenidate is contraindicated in patients with poorly controlled arterial hypertension, symptomatic coronary heart disease, arrhythmia, or epilepsy, while modafinil must be avoided in patients with psychosis and severe affective disorders. Furthermore, more recent reports do not confirm the activity of modafinil. Results of a randomized trial comparing modafinil versus placebo in 208 patients with NSCLC did not show any effect on CRF compared to placebo. ${ }^{55} \mathrm{~A}$ meta-analysis of 1,582 participants treated for $\mathrm{CRF}$ indicated that methylphenidate was superior to placebo for the treatment of CRF, while no efficacy was shown for modafinil. ${ }^{56}$ Preliminary data highlight the role 
of thyrotropin-releasing hormone in CRF treatment and improvement in QoL with patients' manifestations of exhaustion, with exhaustion improving within few hours of treatment. ${ }^{57}$ However, further studies are needed to confirm these results. There is much evidence on erythropoiesis-stimulating agents (ESA) in ameliorating CRF in anemic patients (also with LC) during chemotherapy. ${ }^{58}$ However, anemia is not the only cause of CRF, and these drugs are characterized by a toxicity profile that must be taken into account. Sleeping agents are frequently used to cope with CRF and insomnia in patients with several types of cancer, although there are no results clearly supporting this approach. Interesting data were derived from the use of melatonin agonists in patients with LC receiving chemotherapy. ${ }^{59,60}$ However, further studies need to be performed to establish this effect.

\section{Natural remedies}

Ginseng is one of the most valuable herbs and has been used for more than 5,000 years in oriental medicine. In the United States, it is currently one of the most widely used food supplements. Two types of ginseng are commercially available: American ginseng (Panax quinquefolius) and Asian ginseng (Panax ginseng), and several studies have shown that both help cope with fatigue. ${ }^{61-63}$ A recent trial investigated the therapeutic effects of fermented red ginseng (FRG) extract in 60 patients with NSCLC treated with chemotherapy. FRG was administered for 60 days and significantly improved the Fatigue Symptom Inventory score, psychological status, physical conditions, and QoL; it was also shown to have a positive impact on treatment toxicity profile. ${ }^{64}$ Preliminary data show the ability of purified dry extract of Paullinia cupana (guaraná, PC-18) to help with CRF in patients with solid tumors, including LC. ${ }^{65,66}$ Guaraná is an Amazonian plant; its main active ingredient is caffeine, but with slower release compared to that of pure coffee. Yiqi Jianpi Huaji Decoction is a traditional Chinese medicinal formula consisting of 12 natural ingredients and has recently been associated with efficacy in treating CRF in LC patients receiving chemotherapy. Among 124 patients, 63 were assigned to "the treatment group" and 61 cases to the control group; all received chemotherapy regimens according to their conditions. Patients in the treatment group took Yiqi Jianpi Recipe (YJR) decoction from the first day of chemotherapy, one dose per day, for two consecutive weeks, while those in the control group took no Chinese medical decoction. The trial suggests that YJD decoction could significantly relieve CRF in LC patients, with a significant impact on QoL. ${ }^{67}$

\section{Nonpharmacological treatments and complementary therapies}

Several tools have been proven to be useful in alleviating CRF without medications. Two recent meta-analyses recommend certain specific psychosocial interventions and physical exercise in several cancers, including LC. Physical exercise, negatively perceived in the past, is currently considered the key element in the nonpharmacological management for CRF $^{68,69}$ Data are more robust in preoperative regimen and in survivors. ${ }^{70,71}$ Physical activity has been associated with improvements of QoL, fatigue, and functional capacity in various groups of cancer survivors. ${ }^{72}$ After surgery, a significantly reduced peak oxygen consumption per unit time $\left(\mathrm{VO}_{2}\right)$ with a decrease of patient's ability to tolerate exercise has been reported..$^{73,74}$ Therefore, pulmonary rehabilitation programs for postoperative patients with LC have shown an improvement in functional ability and a greater adherence to exercise capacity. In early-stage LC, emerging evidences suggest that routine exercise is associated with improvements in QoL and fatigue. ${ }^{74,75}$ However, a validated exercise regimen has not been clearly defined for perioperative or advancedstage LC. Several studies confirmed that increased physical activity may improve cluster symptoms and fatigue in patients with LC in the perioperative setting, although the location, duration, and intensity of exercise are not yet defined ${ }^{76-78} \mathrm{Cur}-$ rently, the official guidelines of the American Cancer Society, the National Comprehensive Cancer Network, and American College of Sports Medicine recommend routine physical activity in NSCLC patients, when feasible. ${ }^{79-81}$ In addition, in a translational context, physical exercise could be studied in relation to the histological subtype and the genetic/molecular profile to identify patient groups more responsive to treatment. ${ }^{82}$ The main recommended psychosocial interventions for CFR include cognitive behavioral therapeutic approaches, psychoeducation, topical counseling, energy conservation and activity management, and methods for the promotion and reinforcement of regeneration. ${ }^{83,84}$ However, these data were derived from studies of mixed tumors (mainly women with breast cancer). Mindfulness-based stress reduction (MBSR) is an interesting psychosocial intervention, and this technique was applied in a small group of patients with advanced-stage LC. The qualitative analysis showed that the training could instigate a process of change in participants. Significant differences were not found in pulmonary symptoms, fatigue, and pain. Although mean scores of anxiety and depressive symptoms in both patients and partners decreased after MBSR, these changes were not statistically significant. ${ }^{85}$ Data 
from a randomized controlled trial are expected (MILON study): ${ }^{86}$ this trial compares MBRS with a standard approach in reducing psychological distress and improving QoL in patients with LC and their partners. The assessment of QoL will provide us clear details on the effect of MBRS on CRF in LC patients. Some studies showed that acupuncture could relieve pain, fatigue, and dyspnea in LC patients during all phases of the disease. ${ }^{87-89}$ Acupressure has been evaluated in two studies for its effect on CRF reaching interesting results. A pilot trial evaluated the effects of acupressure on fatigue in 57 LC patients receiving six cycles of chemotherapy: they were randomized into three groups, one with acupressure with essential oils, a second with only acupressure, and a third group with sham acupressure. All subjects received acupressure once every morning for 5 months. Subjects who received acupressure with essential oils and acupressure had significantly less fatigue in daily living activities and a better quality of sleep at day 1 , cycle three, than subjects who received sham acupressure. ${ }^{90}$ Several other complementary therapy modalities can be helpful in improving fatigue and QoL of patients with LC, such as hypnosis, yoga, massage therapy, and Tai Chi. ${ }^{91-93}$

\section{Early palliative care in LC}

The goal of palliative care is to relieve suffering and promote QoL for patients and families. In the past, palliative care usually began at the end of active treatment. Practice guidelines from the World Health Organization and leadership from the oncology and palliative care communities advocate a different model of palliative care, that could be introduced from the point of diagnosis of life-threatening illness. ${ }^{94}$ Some authors evaluated early palliative care (EPC) in LC as having a positive benefit in QoL and physical symptoms such as pain and depression, already defined as symptoms associated with CRF. ${ }^{95-97}$ In addition, EPC may promote QoL by improving management of symptoms due to medical comorbidities such as congestive heart failure and COPD, which are often present in these patients. More data are clearly needed to identify the valid integration methods of EPC and active care.

\section{Summary and conclusion}

$\mathrm{CRF}$ is the most common and debilitating symptom in patients with cancers, including LC. ${ }^{5,6}$ In the entire history of LC, from diagnosis until the end of life, fatigue is present in $57 \%-100 \%$ of patients, which has a huge influence on QoL. 9, 12,26,39,40 The incidence of fatigue can change depending on the time of the disease in which it is evaluated and on coexistence of comorbidity, cluster symptoms, and treatments, which can improve or worsen the situation. Fatigue can be primary, when related to the tumor, while it is defined as secondary if it is due to treatment, nutritional status, laboratory abnormalities, use/abuse of substance, and/or comorbidities. ${ }^{13-17}$ A careful screening by using validated scales (quantitative and semiquantitative) is recommended from the time of diagnosis. ${ }^{18}$ No dedicated scale is standardized for LC, and the BFI is the most widely used scale. There are interesting data on predictive biomarkers of primary CRF in NSCLC: plasma levels of TNF- $\alpha$ and IL-1 seem to be correlated with CRF. ${ }^{19}$ Several studies have identified the concomitance of some symptoms in patients with LC, such as anxiety, depression, fatigue, and sleep disturbances, that are commonly treated as separate entities, even though there are evidences suggesting their close connection, also through the same biological pathways. ${ }^{20,22,23,52}$ A close link exists between pain and fatigue and among breathing symptoms and fatigue. ${ }^{6}$ The vast majority of patients with LC present with comorbidities, such as COPD and heart diseases, that can worsen the CRF. Fatigue is not exclusively reported during the treatment of LC and at the end of life, and also for this reason, practice guidelines from the World Health Organization and leadership from the oncology and palliative care communities proposed the introduction of EPC in all cancer patients, including those with LC. ${ }^{94}$ Several studies have evaluated fatigue in LC survivors after radical resection. ${ }^{12,26-35,37}$ The prevalence of fatigue ranges from $60 \%$ to $70 \%$ at 4 months after thoracotomy. ${ }^{30}$ Fatigue, small impact in lung function, anxiety, depression, and decreased physical activity have been observed after surgical and adjuvant treatments. ${ }^{36-38}$ Some authors have reported a resolution of symptoms at 3-6 months after surgery, while other papers observed persistence of these symptoms for years. ${ }^{33-35}$ The management of fatigue and its cluster symptoms becomes essential for the QoL care of patients with LC at any stage of the disease. Up to now, no standard treatment is recommended to cope with fatigue, and $4 \mathrm{mg}$ of dexamethasone is the only drug approved for $\mathrm{CRF}^{7}$ The use of psychostimulant agents is burdened by significant side effects, and modafinil use in LC patients has not achieved the expected results for the treatment of CRF. ${ }^{53-56}$ Sleeping and antidepressant agents are often prescribed without any evidence supporting their use in this context. $^{59,60}$ The administration of ESA can relieve CRF, but only in anemic patients undergoing chemotherapy. ${ }^{58}$ Natural remedies such as ginseng, ${ }^{61-64}$ cognitive behavioral therapeutic approaches, psychoeducation, topical counseling, ${ }^{83,84}$ energy conservation as MBSR, ${ }^{85,86}$ acupuncture, ${ }^{87-89}$ acupressure, ${ }^{90}$ hypnosis, yoga, massage therapy, and Tai Chi exercise, ${ }^{91-93}$ have been described as valuable aids in the treatment of CRF in LC patients. Physical exercise is a nonpharmacological 
treatment for fatigue, with more evidence in LC at any stage. Several studies have confirmed that increased physical activity may improve cluster symptoms and fatigue in patients with early- and advanced-stage LC, even without a precise schema for the application of this technique. ${ }^{68-82} \mathrm{~A}$ proposal for CRF management in patients with LC is described in Table 2. Data present in literature are often reported in a mixed group of tumors, not taking into account the pecu-

Table 2 Management of CRF in patients with lung cancer

Screening
When From the diagnosis

\begin{tabular}{|c|c|c|c|}
\hline \multicolumn{2}{|c|}{ Screening } & \multicolumn{2}{|l|}{ Revaluations } \\
\hline When & From the diagnosis & $\begin{array}{l}\text { Lung cancer treated with surgery and/ } \\
\text { or neoadjuvant/adjuvant therapy }{ }^{\mathrm{a}} \text { or with } \\
\text { chemoradiotherapy alone }\end{array}$ & Metastatic LC \\
\hline How & $\begin{array}{l}\text { Use of validated scales for fatigue: }{ }^{18} \\
\text { BFI (widely used in trials in LC), FACT-F, } \\
\text { CFS, MFI } \\
\text { Performance status evaluation: KPS } \\
\text { Use of validated scales for QoL: }{ }^{5} \text { EORTC } \\
\text { SF-36 QLQ-C30, SF-36 questionnaire, } \\
\text { ESAS, others } \\
\text { Use of validated scales for pain: }:^{20,21,23} \text { VAS } \\
\text { pain, NRS pain } \\
\text { Sleep quality: }:^{23} \text { sleep duration, trouble } \\
\text { falling asleep, wake up feeling exhausted, } \\
\text { sleepy during the day } \\
\text { Assessment of comorbidities: }{ }^{22,28,29,31} \\
\text { COPD, CVD, endocrine disorders } \\
\text { (thyroid disease), anxiety-depressive } \\
\text { syndrome, others } \\
\text { Daily use of drugs: }{ }^{13-17} \text { Opioids, } \\
\text { benzodiazepines, neuroleptic, others } \\
\text { Abuse of substances: }{ }^{13-17} \text { Drugs, alcohol } \\
\text { Laboratory tests: }{ }^{13-17} \text { Blood count; thyroid, } \\
\text { liver, and kidney function } \\
\text { Presence of cluster symptoms: }{ }^{20,21,23,52} \\
\text { Anxiety, depression (use HADS), insomnia, } \\
\text { somnolence } \\
\text { Presence of respiratory cluster symptoms: } \\
\text { Cough, breathlessness } \\
\text { Measuring lung function with PFTs: }:^{27} \\
\text { Spirometry to evaluate FEV,/FVC } \\
\text { Assessment of physical activity: }: 8-73,74-82 \\
\text { Type of activity before and after the } \\
\text { diagnosis. Current limitations } \\
\text { Other factors:45,46 ethnicity, socioeconomic } \\
\text { and social situation, family relationships }\end{array}$ & $\begin{array}{l}\text { Assessment for fatigue, pain, anxiety, } \\
\text { depression, insomnia, somnolence and } \\
\text { respiratory cluster symptoms at regular } \\
\text { intervals in time (for each symptom it is } \\
\text { recommended to always use the same scale) } \\
\text { Performance Status (KPS) at regular } \\
\text { intervals in time } \\
\text { Measuring lung function with PFTs at regular } \\
\text { intervals in time } \\
\text { Assessment of physical activity } \\
\text { Evaluation of symptoms related to adjuvant } \\
\text { chemotherapy (sensory neuropathy to the } \\
\text { legs) }\end{array}$ & $\begin{array}{l}\text { Assessment for fatigue, pain, anxiety, } \\
\text { depression, insomnia, somnolence, and } \\
\text { respiratory cluster symptoms at regular } \\
\text { intervals in time during treatment (for each } \\
\text { symptom, it is recommended to always use } \\
\text { the same scale) } \\
\text { Performance status (KPS) at each clinic visit } \\
\text { Measuring lung function with PFTs at regular } \\
\text { intervals in time if stable disease and no } \\
\text { obvious clinic progression } \\
\text { Assessment of physical activity } \\
\text { Evaluation of symptoms related to } \\
\text { chemotherapy, target therapy and/or } \\
\text { radiotherapy (if in use active therapies) }\end{array}$ \\
\hline \multicolumn{3}{|c|}{ Proposed treatment } & Proposed treatment \\
\hline \multicolumn{3}{|c|}{ Promote pulmonary rehabilitation programs if there is a presence of deficits } & Promote pulmonary rehabilitation programs \\
\hline \multicolumn{3}{|c|}{ Promote physical activity based on the KPS and comorbidity } & if there is a presence of deficits (patients with \\
\hline \multicolumn{3}{|c|}{ Pain control (if present) } & COPD) \\
\hline \multicolumn{3}{|c|}{ Psychotherapy (if present distress) ${ }^{b}$} & Promote physical activity based on the KPS \\
\hline \multicolumn{3}{|c|}{ Multidisciplinary approach ${ }^{c}$} & and comorbidity \\
\hline \multicolumn{3}{|c|}{ Natural remedies, complementary therapies ${ }^{d}$} & Pain control (if present) \\
\hline \multirow[t]{2}{*}{ EPC } & & & Psychotherapy (if present distress) ${ }^{b}$ \\
\hline & & & $\begin{array}{l}\text { Multidisciplinary approach }{ }^{c} \\
\text { Natural remedies, complementary therapies } \\
\text { Palliative care }\end{array}$ \\
\hline
\end{tabular}

Notes: ${ }^{2}$ Chemotherapy and/or radiotherapy; ${ }^{b}$ cognitive behavioral therapeutic approaches, psychoeducation, topical counseling, energy conservation and activity management, and methods for the promotion and reinforcement of regeneration; cif fatigue associated and/or worsened by other comorbidities (such as heart failure, thyroid disease); thypnosis, yoga, and massage therapy.

Abbreviations: LC, lung cancer; BFl, Brief Fatigue Inventory; FACT-F, Functional Assessment of Cancer Therapy-Fatigue; CFS, Cancer Fatigue Scale; MFI, Multidimensional Fatigue Inventory; KPS, Karnofsky Performance Status; QoL, quality of life; EORTC SF-36 QLQ-C30, European Organization for Research and Treatment of Cancer Quality of Life Questionnaire-Core 30; ESAS, Edmonton Symptom Assessment System; VAS, Visual Analog Scale; NRS, Numeric Rating Scale; HADS, Hospital Anxiety and Depression Scale; COPD, chronic obstructive pulmonary disease; CVD, cardiovascular diseases; PFTs, pulmonary function tests; FEV/FVC, forced vital capacity ratio; EPC, early palliative care. 
liarity of LC, which is frequently diagnosed in patients with several comorbidities; this can have a significant impact on fatigue. These data, together with the unpredictability of this tumor, should stimulate clinicians and researchers to develop a customized screening and treatment for CRF in patients with LC.

\section{Disclosure}

The authors report no conflicts of interest in this work.

\section{References}

1. Torre LA, Bray F, Siegel RL, Ferlay J, Lortet-Tieulent J, Jemal A. Global cancer statistics, 2012. CA Cancer J Clin. 2015;65(2):87-108.

2. Fitch MI, Steele R. Supportive care needs of individuals with lung cancer. Can Oncol Nurs J. 2010;20:15-22.

3. Nelson JE, Gay EB, Berman AR, Powell CA, Salazar-Schicchi J, Wisnivesky JP. Patients rate physician communication about lung cancer. Cancer. 2011;117:5212-5220.

4. Cheville AL, Novotny PJ, Sloan JA, et al. Fatigue, dyspnea, and cough comprise a persistent symptom cluster up to five years after diagnosis with lung cancer. J Pain Symptom Manage. 2011;42(2): 202-212.

5. Roulston A, Bickerstaff D, Haynes T, Rutherford L, Jones L. A pilot study to evaluate an outpatient service for people with advanced lung cancer. Int J Palliat Nurs. 2012;18:225-233.

6. Molassiotis A, Lowe M, Blackhall F, Lorigan P. A qualitative exploration of a respiratory distress symptom cluster in lung cancer: cough, breathlessness and fatigue. Lung Cancer. 2011;71:94-102.

7. NCCN Clinical practice guidelines in oncology, cancer-related fatigue version I.2016. Available from: http://www.nccn.org/professionals/ physician_gls/pdf/fatigue.pdf. Accessed March 16, 2016.

8. Sanders SL, Bantum EO, Owen JE, Thornton AA, Stanton A. Supportive care needs in patients with lung cancer. Psychooncology. 2010;19:480-489.

9. Hofman M, Ryan JL, Figueroa-Moseley CD, Jean-Pierre P, Morrow GR. Cancer-related fatigue: the scale of the problem. Oncologist. 2007;12(Suppl 1):4-10.

10. Graves KD, Arnold SM, Love CL, Kirsh KL, Moore PG, Passik SD. Distress screening in a multidisciplinary lung cancer clinic: prevalence and predictors of clinically significant distress. Lung Cancer. 2007; 55:215-224.

11. Berger AM, Mitchell SA, Jacobsen PB, Pirl WF. Screening, evaluation, and management of cancer-related fatigue: Ready for implementation to practice? CA Cancer J Clin. 2015;65(3):190-211.

12. Bower JE, Bak K, Berger A, et al. Screening, assessment, and management of fatigue in adult survivors of cancer: an American Society of Clinical Oncology Clinical Practice Guideline Adaptation. J Clin Oncol. 2014;32(17):1840-1850.

13. Peuckmann V, Elsner F, Krumm N, Trottenberg P, Radbruch L. Pharmacological treatments for fatigue associated with palliative care. Cochrane Database Syst Rev. 2010;10:CD006788.

14. Jager A, Sleijfer S, van der Rijt CC. The pathogenesis of cancer related fatigue: could increased activity of pro-inflammatory cytokines be the common denominator? Eur J Cancer. 2008;44(2):175-181.

15. Kamath J, Yarbrough GG, Prange AJ Jr, Winokur A. The thyrotropinreleasing hormone (TRH)-immune system homeostatic hypothesis. Pharmacol Ther. 2009;121(1):20-28.

16. Payne JK. Altered circadian rhythms and cancer-related fatigue outcomes. Integr Cancer Ther. 2011;10(3):221-233.

17. Bower JE, Ganz PA, Irwin MR, Arevalo JM, Cole SW. Fatigue and gene expression in human leukocytes: increased NF- $\mathrm{KB}$ and decreased glucocorticoid signaling in breast cancer survivors with persistent fatigue. Brain Behav Immun. 2011;25(1):147-150.
18. Minton O, Stone P. A systematic review of the scales used for the measurement of cancer-related fatigue (CRF). Ann Oncol. 2009;20: $17-25$.

19. Sha F, Zhuang S, Zhou L, et al. Biomarkers for cancer-related fatigue and adverse reactions to chemotherapy in lung cancer patients. Mol Clin Oncol. 2015;3(1):163-166.

20. Reyes-Gibby CC, Wu X, Spitz M, et al. Molecular epidemiology, cancer-related symptoms, and cytokines pathway. Lancet Oncol. 2008;9(8):777-785.

21. Lutz S, Norerell R, Bertucio C, et al. Symptom frequency and severity in patients with metastatic or locally recurrent lung cancer: a prospective study using the lung cancer symptom scale in a community hospital. $J$ Palliat Med. 2001;4(2):157-165.

22. Hopwood P, Stephens RJ. Depression in patients with lung cancer: prevalence and risk factors derived from quality-of-life data. $J$ Clin Oncol. 2000;18(4):893-903.

23. Morita T, Fujimoto K, Tei Y. Palliative care team: the first year audit in Japan. J Pain Symptom Manage. 2005;29(5):458-465.

24. Reyes-Gibby CC, Swartz MD, Yu X. Symptom clusters of pain, depressed mood, and fatigue in lung cancer: assessing the role of cytokine genes. Support Care Cancer. 2013;21(11):3117-3125.

25. Yorke J, Lloyd-Williams M, Smith J, et al. Management of the respiratory distress symptom cluster in lung cancer: a randomized controlled feasibility trial. Support Care Cancer. 2015;23(11):3373-3384.

26. The National Coalition for Cancer Survivorship. Available from: http:// www.canceradvocacy.org/about-us/our-history/. Accessed July 9, 2014.

27. Sarna L, Padilla G, Holmes C, et al. Quality of life of long-term survivors of non-small-cell lung cancer. J Clin Oncol. 2002;20:2920-2929.

28. Hung R, Krebs P, Coups EJ, et al. Fatigue and functional impairment in early-stage non-small cell lung cancer survivors. J Pain Symptom Manage. 2011;41:426-435.

29. Ozturk A, Sarihan S, Ercan I, Karadag M. Evaluating quality of life and pulmonary function of long-term survivors of non-small cell lung cancer treated with radical or postoperative radiotherapy. Am J Clin Oncol. 2009;32:65-72.

30. Sarna L, Cooley ME, Brown JK, et al. Symptom severity 1 to 4 months after thoracotomy for lung cancer. Am J Crit Care. 2008;17:455-467.

31. Huang X, Zhou $\mathrm{W}, Z$ Zhang Y. Features of fatigue in patients with early-stage non-small cell lung cancer. J Res Med Sci. 2015;20(3):268-272.

32. Poghosyan H, Sheldon LK, Leveille SG, Cooley ME. Health-related quality of life after surgical treatment in patients with non-small cell lung cancer: a systematic review. Lung Cancer. 2013;81:11-26.

33. Win T, Sharples L, Wells FC, et al. Effect of lung cancer surgery on quality of life. Thorax. 2005;60:234-238.

34. Brunelli A, Socci L, Refai M, et al. Quality of life before and after major lung resection for lung cancer: a prospective follow-up analysis. Ann Thorac Surg. 2007;84:410-416.

35. Kenny PM, King MT, Viney RC, et al. Quality of life and survival in the 2 years after surgery for non small-cell lung cancer. J Clin Oncol. 2008;26:233-241.

36. Winton T, Livingston R, Johnson D, et al. Vinorelbine plus cisplatin vs. observation in resected non-small-cell lung cancer. $N$ Engl J Med. 2005;352:2589-2597.

37. Ilonen I, Rauma V, Rasanen JV, Salo JA. Long-term lung cancer survivors have permanently decreased quality of life following surgery [abstract 260]. Interact CardioVasc Thorac Surg. 2013;17(Suppl 2):S132.

38. Gonzalez BD, Jacobsen PB. Depression in lung cancer patients: the role of perceived stigma. Psychooncology. 2012;21(3):239-246.

39. Ahlberg K, Ekman T, Gaston-Johansson F, Mock V. Assessment and management of cancer-related fatigue in adults. Lancet. 2003;362: 640-650.

40. Lee YH, Tsai YF, Lai YH, Tsai CM. Fatigue experience and coping strategies in Taiwanese lung cancer patients receiving chemotherapy. J Clin Nurs. 2008;17:876-883.

41. Maguire R, Papadopoulou C, Kotronoulas G, Simpson MF, McPhelim J, Irvine L. A systematic review of supportive care needs of people living with lung cancer. Eur J Oncol Nurs. 2013;17(4):449-464. 
42. Lemonnier I, Guillemin F, Arveux P, et al. Quality of life after the initial treatments of non-small cell lung cancer: a persistent predictor for patients' survival. Health Qual Life Outcomes. 2014;12:73.

43. Dimsdale JE, Ancoli-Israel S, Ayalon L, Elsmore TF, Gruen W. Taking fatigue seriously, II: variability in fatigue levels in cancer patients. Psychosomatics. 2007;48:247-252.

44. Jim HS, Small B, Faul LA, Franzen J, Apte S, Jacobsen PB. Fatigue, depression, sleep, and activity during chemotherapy: daily and intraday variation and relationships among symptom changes. Ann Behav Med 2011;42:321-333.

45. Wright F, D'Eramo Melkus G, Hammer M, et al. Predictors and trajectories of morning fatigue are distinct from evening fatigue. J Pain Symptom Manage. 2015;50(2):176-189.

46. Kober KM, Cooper BA, Paul SM, et al. Subgroups of chemotherapy patients with distinct morning and evening fatigue trajectories. Support Care Cancer. Epub September 11, 2015.

47. Dhruva A, Aouizerat B, Cooper B, et al. Cytokine gene associations with self-report ratings of morning and evening fatigue in oncology patients and their family caregivers. Biol Res Nurs. 2015;17:175-184.

48. Iwase S, Kawaguchi T, Tokoro A, et al. Assessment of cancer-related fatigue, pain, and quality of life in cancer patients at palliative care team referral: a multicenter observational study (JORTC PAL-09). PLoS One. 2015;10(8):e0134022.

49. Li N, Yang L, Ou W, Zhang L, Zhang SL, Wang SY. Meta-analysis of EGFR tyrosine kinase inhibitors compared with chemotherapy as second-line treatment in pretreated advanced non-small cell lung cancer. PloS One. 2014;9(7):e102777.

50. Novello S, Capelletto E, Cortinovis D, et al. Italian multicenter survey to evaluate the opinion of patients and their reference clinicians on the "tolerance" to targeted therapies already available for non-small cell lung cancer treatment in daily clinical practice. Transl Lung Cancer Res. 2014;3(3):173-180.

51. Minton O, Richardson A, Sharpe M, Hotopf M, Stone P. Drug therapy for the management of cancer-related fatigue. Cochrane Database Syst Rev. 2010;7:CD006704.

52. Yennurajalingam S, Frisbee-Hume S, Palmer JL, et al. Reduction of cancer-related fatigue with dexamethasone: a double-blind, randomized, placebo-controlled trial in patients with advanced cancer. J Clin Oncol. 2013;31(25):3076-3082

53. Breitbart W, Alici Y. Psychostimulants for cancer-related fatigue. J Natl Compr Canc Netw. 2010;8(8):933-942.

54. Cooper MR, Bird HM, Steinberg M. Efficacy and safety of modafinil in the treatment of cancer-related fatigue. Ann Pharmacother. 2009; 43(4):721-725.

55. Spathis A, Fife K, Blackhall F, et al. Modafinil for the treatment of fatigue in lung cancer: results of a placebo-controlled, double-blind, randomizedtrial. J Clin Oncol. 2014;32(18):1882-1888.

56. Qu D, Zhang Z, Yu X, Zhao J, Qiu F, Huang J. Psychotropic drugs for the management of cancer-related fatigue: a systematic review and meta-analysis. Eur J Cancer Care (Engl). Epub October 21, 2015.

57. Kamath J, Feinn R, Winokur A. Thyrotropin-releasing hormone as a treatment for cancer-related fatigue: a randomized controlled study. Support Care Cancer. 2012;20(8):1745-1753.

58. Vansteenkiste J1, Glaspy J, Henry D, et al. Benefits and risks of using erythropoiesis-stimulating agents (ESAs) in lung cancer patients: study-level and patient-level meta-analyses. Lung Cancer. 2012;76(3):478-485

59. Lissoni P, Chilelli M, Villa S, et al. Five years survival in metastatic non-small cell lung cancer patients treated with chemotherapy alone or chemotherapy and melatonin: a randomized trial. J Pineal Res. 2003;35:12-15.

60. Lissoni P, Paolorossi F, Ardizzoia A, et al. A randomized study of chemotherapy with cisplatin plus etopside versus chemoendocrine therapy with cisplatin, etoposide and the pineal hormone melatonin as a first-line treatment of advanced non-small cell lung cancer patients in a poor clinical state. J Pineal Res. 1997;23:15-19.
61. Jia L, Zhao Y. Current evaluation of the millennium phytomedicine ginseng (I): etymology, pharmacognosy, phytochemistry, market and regulations. Curr Med Chem. 2009;16:2475-2484.

62. Barton DL, Soori GS, Bauer BA, et al. Pilot study of Panax quinquefolius (American ginseng) to improve cancer-related fatigue: a randomized, double-blind, dose-finding evaluation: NCCTG trial N03CA. Support Care Cancer. 2010;18:179-187.

63. Younus J, Collins A, Wang X, et al. A double blind placebo controlled pilot study to evaluate the effect of ginseng on fatigue and quality of life in adult chemo-naïve cancer patients. Proc Am Soc Clin Oncol. 2003;22:Abstract 2947.

64. Jiang SL, Liu HJ, Liu ZC, et al. Adjuvant effects of fermented red ginseng extract on advanced non-small cell lung cancer patients treated with chemotherapy. Chin J Integr Med. Epub July 4, 2015.

65. de Oliveira Campos MP, Riechelmann R, Martins LC, et al. Guarana (Paullinia cupana) improves fatigue in breast cancer patients undergoing systemic chemotherapy. J Altern Complement Med. 2011; 17(6):505-512.

66. del Giglio AB, Cubero Dde I, Lerner TG, et al. Purified dry extract of Paullinia cupana (guaraná) (PC-18) for chemotherapy-related fatigue in patients with solid tumors: an early discontinuation study. J Diet Suppl. 2013;10(4):325-334.

67. Wang X, You J. Treating Cancer-related fatigue after chemotherapy in lung cancer patients by Yiqi Jianpi recipe: a clinical study. Zhongguo Zhong Xi Yi Jie He Za Zhi. 2015;35(9):1069-1073.

68. Cramp F, Byron-Daniel J. Exercise for the management of cancer-related fatigue in adults. Cochrane Database Syst Rev. 2012;11:CD006145.

69. Paramanandam VS, Dunn V. Exercise for the management of cancerrelated fatigue in lung cancer: a systematic review. Eur J Cancer Care. 2015;24(1):4-14.

70. Crandall K, Maguire R, Campbell A, et al. Exercise intervention for patients surgically treated for non-small cell lung cancer (NSCLC): a systematic review. Surg Oncol. 2014;23:17-30.

71. Rodriguez-Larrad A, Lascurain-Aguirrebena I, Abecia-Inchaurregui LC, et al. Perioperative physiotherapy in patients undergoing lung cancer resection. Interact Cardiovasc Thorac Surg. 2014;19:269-281.

72. Speck RM, Courneya KS, Masse LC, et al. An update of controlled physical activity trials in cancer survivors: a systematic review and meta-analysis. J Cancer Surviv. 2010;4:87-100.

73. Jones LW, Peddle CJ, Eves ND, et al. Effects of presurgical exercise training on cardiorespiratory fitness among patients undergoing thoracic surgery for malignant lung lesions. Cancer. 2007;110:590-598.

74. Granger CL, McDonald CF, Irving L, et al. Low physical activity levels and functional decline in individuals with lung cancer. Lung Cancer. 2014;83(2):292-299.

75. Lin YY, Rau KM Lin CC. Longitudinal study on the impact of physical activity on the symptoms of lung cancer survivors. Support Care Cancer. 2015;23(12):3545-3553.

76. Quist M, Rorth M, Langer S, et al. Safety and feasibility of a combined exercise intervention for inoperable lung cancer patients undergoing chemotherapy: a pilot study. Lung Cancer. 2012;75:203-208.

77. Henke CC, Cabri J, Fricke L, et al. Strength and endurance training in the treatment of lung cancer patients in stages IIIA/IIIB/IV. Support Care Cancer. 2014;22:95-101.

78. Cheville AL, Kollasch J, Vandenberg J, et al. A home-based exercise program to improve function, fatigue, and sleep quality in patients with Stage IV lung and colorectal cancer: a randomized controlled trial. J Pain Symptom Manage. 2013;45:811-821.

79. Denlinger CS, Ligibel JA, Are M, et al. NCCN Clinical Practice Guidelines in Oncology: Survivorship. Version 1.2015. Available from: http://www.nccn.org/professionals/physician_gls/f_guidelines. asp\#supportive. Accessed July 30, 2015.

80. American Cancer Society. ACS Guidelines for Nutrition and Physical Activity for Cancer Prevention. Available from: http://www.cancer.org/ healthy/eathealthygetactive/csguidelinesonnutritionphysicalactivityforcancerprevention/acsguidelines-on-nutrition-and-physical-activityfor-cancer prevention-summary. Accessed August 14, 2014. 
81. Garber CE, Blissmer B, Deschenes MR, et al. American College of Sports Medicine position stand. Quantity and quality of exercise for developing and maintaining cardiorespiratory, musculoskeletal, and neuromotor fitness in apparently healthy adults: guidance for prescribing exercise. Med Sci Sports Exerc. 2011;43:1334-1359.

82. Jones LW. Precision oncology framework for investigation of exercise as treatment for cancer. J Clin Oncol. 2015;33(35):4134-4137.

83. Kangas M, Bovbjerg DH, Montgomery GH. Cancer-related fatigue: a systematic and meta-analytic review of non-pharmacological therapies for cancer patients. Psychol Bull. 2008;134(5):700-741.

84. Goedendorp MM, Gielissen MF, Verhagen CA, Bleijenberg G. Psychosocial interventions for reducing fatigue during cancer treatment in adults. Cochrane Database Syst Rev. 2009;(1):CD006953.

85. van den Hurk DG, Schellekens MP, Molema J, Speckens AE, van der Drift MA. Mindfulness-based stress reduction for lung cancer patients and their partners: results of a mixed methods pilot study. Palliat Med. 2015;29(7):652-660.

86. Schellekens MP, van den Hurk DG, Prins JB, et al. Study protocol of a randomized controlled trial comparing mindfulness-based stress reduction with treatment as usual in reducing psychological distress in patients with lung cancer and their partners: the MILON study. BMC Cancer. 2014;14:3

87. Javdan B, Cassileth B. Acupuncture research at Memorial Sloan Kettering Cancer Center. J Acupunct Meridian Stud. 2015;8(3): 115-121.

88. Kasymjanova G, Grossman M, Tran T, et al. The potential role for acupuncture in treating symptoms in patients with lung cancer: an observational longitudinal study. Curr Oncol. 2013;20(3):152-157.

89. Deng GE, Rausch SM, Jones LW, et al. Complementary therapies and integrative medicine in lung cancer: diagnosis and management of lung cancer, 3rd ed: American College of Chest Physicians evidence-based clinical practice guidelines. Chest. 2013;143(5 Suppl): e420S-e436S
90. Tang WR, Chen WJ, Yu CT, et al. Effects of acupressure on fatigue of lung cancer patients undergoing chemotherapy: an experimental pilot study. Complement Ther Med. 2014;22(4):581-591.

91. McCall M, McDonald M, Thorne S, Ward A, Heneghan C. Yoga for health-related quality of life in adult cancer: a randomized controlled feasibility study. Evid Based Complement Alternat Med. 2015; 2015:816820

92. Pachman DR, Price KA, Carey EC. Non pharmacologic approach to fatigue in patients with cancer. Cancer J. 2014;20(5):313-318.

93. Zhang LL, Wang SZ, Chen HL, Yuan AZ. Tai Chi exercise for cancer-related fatigue in patients with lung cancer undergoing chemotherapy: a randomized controlled trial. Pain Symptom Manage. 2015;51(3):504-511.

94. World Health Organization. WHO definition of palliative care. Available from: http://www.who.int/cancer/palliative/definition/en/ 2011. Accessed August 14, 2012.

95. Bakitas M, Lyons KD, Hegel MT, et al. Effects of a palliative care intervention on clinical outcomes in patients with advanced cancer: the project enable in randomized controlled trial. JAMA. 2009;302(7):741-749.

96. Temel JS, Greer JA, Muzikansky A, et al. Early palliative care for patients with metastatic non-small cell lung cancer. $N$ Engl J Med. 2010;363(8):733-742.

97. Temel JS, Greer JA, Admane S, et al. Longitudinal perceptions of prognosis and goals of therapy in patients with metastatic non-smallcell lung cancer: results of a randomized study of early palliative care. J Clin Oncol. 2011;29(17):2319-2326.

\section{Publish your work in this journal}

Lung Cancer: Targets and Therapy is an international, peer-reviewed, open access journal focusing on lung cancer research, identification of therapeutic targets and the optimal use of preventative and integrated treatment interventions to achieve improved outcomes, enhanced survival and quality of life for the cancer patient. Seciluic topics covered in the journal include: Epidemiology, detection and screening;
Cellularch and biomarkers; Identification of biotargets and agents with novel Submit your manuscript here: http://www.dovepress.com/lung-cancer-targets--therapy-journal

\section{Dovepress}

mechanisms of action; Optimal clinical use of existing anticancer agents, including combination therapies; Radiation and surgery; Palliative care; Patient adherence, quality of life, satisfaction; Health economic evaluations. The manuscript management system is completely online and includes a very quick and fair peer-review 作 w.dovepress.com/testimonials.php to read real quotes from published authors. 